\title{
Parliamentary Informatics Projects - Who Are Their Users and What Is Their Impact?
}

\author{
Alina Ostling \\ European University Institute, Department of Political \& Social Sciences, Florence, Italy, \\ Email: alina.ostling@eui.eu Homepage: http://alinaostling.wordpress.com
}

\begin{abstract}
The past decade has brought a boom of online initiatives that monitor the performance of parliaments - a practice commonly referred to as 'parliamentary informatics'. A recent survey identified 191 organisations monitoring over 80 parliaments worldwide; many of these use digital tools to aggregate information and facilitate citizens' involvement in parliamentary activity (Mandelbaum 2011). At the same time, little is actually known about who uses these platforms and whether they increase the quality of democracy. This paper aims to fill this gap by assessing parliamentary informatics projects in three European countries from the point of view of key democratic dimensions: equality, accountability, and political responsiveness.
\end{abstract}

In particular, the paper shows that parliamentary informatics projects achieve mixed results in terms of democratic quality. Many of the traditionally underrepresented groups in politics have even more limited presence on these online platforms. Accountability - including access to user-friendly, close to real-time, and objective political information that help ordinary citizens to hold their representative accountable - turns out to be the strong point of this type of project. However, users do not consider transparency of information to be enough. Many participants build up significant expectations about the political effects of their engagement. Yet, their expectations are generally disappointed by lack of impact.

Keywords: e-democracy, e-participation, civic engagement, parliamentary informatics, equality, accountability, transparency, political responsiveness.

\section{Introduction}

P arliamentary informatics ${ }^{1}$ is generally defined as the application of information technology to the documentation and dissemination of legislative activity. Moreover, by using new technologies to enable citizens to participate in democratic processes, parliamentary informatics projects qualify as a manifestation of electronic (e)-democracy.

In the past decade, the number and variety of e-democracy projects have grown in Western Europe (Lührs and Molinari 2010). The OECD even talks about an "explosion" of interest in and use of participative web tools and platforms (OECD 2009). Although e-democracy has become an important part of the political landscape in Europe, little is actually known about its effects on European democracies. Citizens' engagement is often assumed to have a uniform positive impact on democracy and on the quality of decision-making, since, at least in theory, e-democracy initiatives enable citizens to set the political agenda and influence policy processes. Many scholars, as well as actors, involved in the implementation of e-democracy projects tend to promote them

\footnotetext{
${ }^{1}$ The Parliamentary Informatics page on Wikipedia - http://en.wikipedia.org/wiki/Parliamentary informatics - is currently a reference point for actors involved in such activities.
} 
rather uncritically and profess that digital technologies enhance inclusiveness, transparency and the quality of political participation.

However, the reality is more ambiguous. Whilst some effects can be foreseen, most edemocracy projects result in complex and mixed impacts on democratic practice, or in no impact at all (Pratchett 2006). Some projects are dominated by a minority of participants or lobby groups; others show poor deliberation quality and are disconnected from policy making (Lührs and Molinari 2010; Wojcik 2007). From the theoretical perspective, it is not clear what democratic standards and outcomes e-democracy is supposed to attain. In practice, participation methods are usually systematised according to structural characteristics, e.g. the number of participants, the etechniques used. and the general intention of the process, but not according to their democratic quality (EIPP 2009). Moreover, the literature so far has focused on descriptions of isolated projects, while there is a need to move towards a comparative evaluation of cases (Åström and Grönlund 2010; Lippa et al. 2008). The comparative analysis of parliamentary informatics cases presented here aims at contributing to filling this gap. Moreover, in scrutinizing e-democracy from the user perspective - than from the more common perspectives of policy-makers and data/tool providers and in addressing democratic quality standards, the paper aims at helping to rebalance the edemocracy debate towards civic over structural and technological characteristics.

The theoretical framework of this paper is based on the 'essentialist' and the 'instrumentalist' approaches (Blanco and Lowndes 2011). The former is rooted in Barber's concept of strong democracy and considers public engagement as an essential feature of democracy (Barber 1984). From this perspective, the main challenge is to assess if participation fulfils certain procedural criteria that ensure its democratic legitimacy. In this paper, the essentialist criteria are operationalised as 'equality' and 'accountability'. Equality is defined as the representativeness of users with respect to their reference population, while the accountability criterion denotes that citizens should be able to access objective and balanced information about the issues discussed in parliaments. From the instrumentalist perspective, the key challenge is to find evidence of the political impact of participation (Blanco and Lowndes 2011). This implies that projects should provide a context in which decision-makers take citizens' opinions into account and try to fulfil their expectations.

Based on previous research in the fields of public participation and e-democracy, this paper examines a number of assumptions about what affects the three democratic quality dimensions of equality, accountability and responsiveness. Firstly, I assume that a country's socio-economic context and its levels of political participation affect the equality among project participants. Secondly, the type of site moderation and the sources of information provided on the project platforms should influence parliamentary accountability. Thirdly, the democratic intentions of the parliamentarians, including the extent of their political support, should affect the parliaments' responsiveness to the input made by users or the civil society groups active on parliamentary informatics platforms.

This theoretical framework is tested through a comparison of parliamentary informatics cases in Italy, France and the UK. The case studies draw on the results of online user surveys and interviews with project stakeholders, as well as an analysis of project documentation and usage statistics.

\section{The Democratic Quality of Parliamentary Informatics Projects}

The paper focuses on three parliamentary informatics projects: OpenParlamento (OP) in Italy, TheyWorkForYou (TWFY) in the UK and NosDéputés (ND) in France. These all offer information and statistics about parliamentary activities, and the possibility of discussing and annotating 
legislative acts online. The project survey data in this paper originate from the author's surveys of OP and ND $(2011)^{2}$, and from Tobias Escher's survey of TWFY (Escher 2011). ${ }^{3}$

\subsection{Equality}

The concept of equality examined in this paper is closely related to Scharpf's notion of inputlegitimacy, which is produced by the inclusive involvement of citizens affected by a political outcome (Barber 1984; Scharpf 1997). This means that a lack of equality among participants poses problems of legitimacy to the political outcomes.

The literature on Internet activism is split between the supporters of the mobilization hypothesis, who think that the Internet can give more space to marginalised groups in politics, and the reinforcement proponents, who believe that it merely reinforces existing elites (Breindl 2010). Online equality is important primarily because where there are strong divergences among people participating offline and online, new configurations of political influence can come about. Alternatively, where the segments involved offline and online converge, existing political inequalities may simply be reinforced (Anduiza et al. 2012).

Previous research in the field of political involvement shows that participation depends greatly on levels of socio-economic development. The literature specifies some social factors that can enhance the quality and results of e-democracy projects: a solid civil society, high levels of political participation, as well as civic literacy and computer skills, and an efficient ICT infrastructure (Anduiza et al. 2012 p. 3). These indicators are assumed to condition the extent to which the projects under study achieve equality among participants, and some of them (not all, due to the limits of space) will be tested in the framework of this paper.

The result of the online surveys among project users show that many citizen groups are underrepresented on parliamentary informatics platforms. Firstly, women only constitute between $16 \%$ $34 \%$ of respondents. The share of women across the three projects reflects what is happening in terms of political participation of women on country levels: the UK shows the best gender-balance, while France and Italy have inferior scores (see Table 1). This implies that the gender inequality pattern discernable in the projects could well be influenced by the state of gender equality in politics at the national levels. It is also noteworthy that, on the country level, the share of women engaged in parliamentary informatics projects tends to be much lower with respect to the share of women in other participatory activities such as demonstrating, petitioning or voting.

\footnotetext{
${ }^{2}$ The data analysis from the surveys is still underway so more influencing variables (e.g. civic literacy of users, ICT skills, the level of citizen mobilisation) will be taken into account in my $\mathrm{PhD}$ thesis.

${ }^{3}$ All the three surveys were carried out in 2011. The author's surveys of OP and ND had a response rate of 9\% (OP: 4,300 sent and 397 responded, ND: 1,070 sent and 99 responded, at least partially). Tobias Escher's survey had a response rate of $8 \%(\mathrm{~N}=903)$.
} 
Table 1: Percentages of politically active women in Italy, France and the UK (Author's surveys 2011, Escher 2011; European Social Survey (ESS) ESS1-2002 ${ }^{4}$; United Nations Statistics Division $2012)^{5}$

\begin{tabular}{|c|c|c|c|}
\hline & Italy & France & UK \\
\hline Contacted politician/government official & 36 & 48 & 49 \\
\hline Taken part in a lawful demonstration & 46 & 48 & 56 \\
\hline Signed a petition & 54 & 53 & 57 \\
\hline Voted in the last national elections & 53 & 53 & 54 \\
\hline Averages across the country-level statistics & 47 & 51 & 54 \\
\hline$\%$ of women among respondents (OP, ND, TWFY) & 16 & 22 & 34 \\
\hline
\end{tabular}

Moreover, the respondents' level of education is well above the national average (see Figure 1). The share of OP respondents who finished university is five-fold with respect to that of Italy's population; while among TWFY and ND respondents double as many have a university degree in comparison to their respective country populations. The existence of many $\mathrm{PhD}$ holders among the OP and ND respondents (7-8\%) versus their co-nationals $(0.002 \%-0.003 \%)$ confirms the tendency of strong higher educational attainment among project users.

At the other end, there are few people with lower education among respondents. The difference between project respondents and country populations is between three and fivefold for those who only attained primary education. In sum, in terms of educational attainment, the respondents are clearly not representative of their country populations.

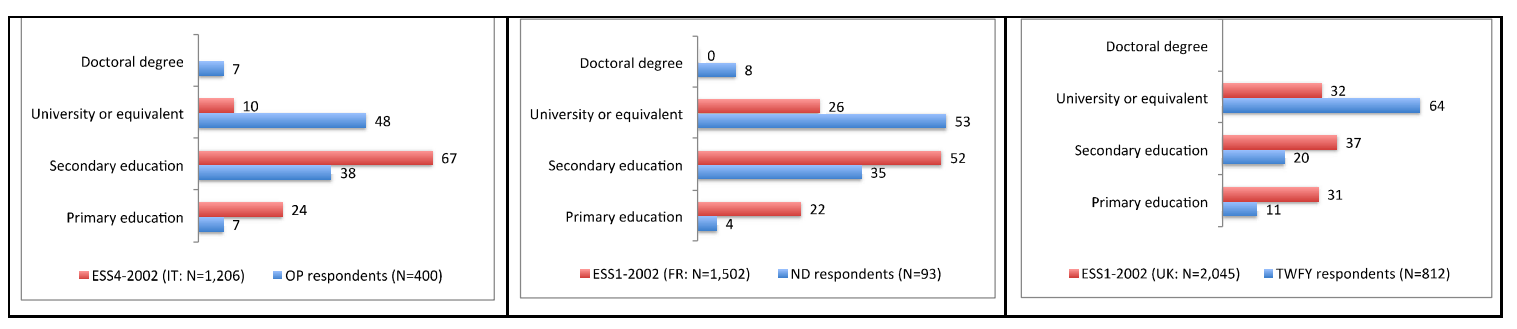

Figure 1: Educational attainment of respondents vs. their respective country populations (\%) (Author's surveys 2011; Escher 20116 ; ESS1-2002; The Long Term Economy 20098)

\footnotetext{
${ }^{4}$ The reason for using such an old round of the ESS (ESS1-2002) is that Italy has not carried out any ESS survey since 2002.

${ }^{5}$ The figures concerning 'Seats held by women in national parliaments' are country-level statistics that represent the proportion of seats held by women in national parliaments, expressed as a percentage of all occupied seats. This indicator covers the single chamber in unicameral parliaments and the lower chamber in bicameral parliaments. It does not cover the upper chamber of bicameral parliaments. Data updated in 2012 (United Nations Statistics Division 2012).
} 
The data where the difference between respondents and the country populations is greatest (i.e. for people with highest and lowest education levels) was compared with the country cohorts in ESS1-2002 who have engaged in alternative forms of political participation. The survey respondents are more similar to the cohort alternatively engaged in politics rather than to their respective country population (see Table 2). Both the politically active cohort and the project respondents have fewer lower-educated and more higher-educated people among them with respect to the country averages. What is more, the inequality levels are greater among the project respondents in comparison to the politically active cohort: the project respondents have even more high-educated and fewer low-educated people among them.

It is also noteworthy that country-patterns are discernable regarding tertiary education, i.e. the lowest number of people with tertiary education is found among (i) the general population in Italy, (ii) the Italians who are politically active, and (iii) the OP respondents. At the same time, the equivalent French cohorts occupy a middling position; and the British ones have the highest level of people who have completed university.

Table 2. The share of persons with (i) less than lower secondary education and (ii) tertiary education who have engaged in politics in alternative ways in Italy, France and the UK (\%) (Authors' surveys 2011; ESS1-2002)

\begin{tabular}{lrrr|rrrr}
\hline & \multicolumn{2}{c|}{$\begin{array}{c}\text { Primary } \\
\text { education }\end{array}$} & \multicolumn{4}{c}{$\begin{array}{c}\text { Tertiary } \\
\text { education }\end{array}$} \\
\hline Averages across the country-level statistics & IT & FR & UK & IT & FR & UK \\
Averages among project respondents (OP, ND, TWFY) & 7 & 4 & 11 & 48 & 53 & 64 \\
Contacted politician/government official & 24 & 22 & 31 & 10 & 26 & 32 \\
Taken part in a lawful demonstration & 12 & 14 & 22 & 18 & 36 & 50 \\
Signed a petition & 7 & 6 & 12 & 20 & 47 & 54 \\
Averages across the three participation indicators & $\mathbf{9}$ & $\mathbf{1 0}$ & $\mathbf{1 7}$ & $\mathbf{1 8}$ & $\mathbf{4 1}$ & $\mathbf{4 8}$ \\
\hline
\end{tabular}

In terms of occupation, the project respondents are quite similar to their co-nationals. Nevertheless, a very low share of respondents does the housework and looks after children or others $(2-3 \%)$, which stands in contrast with the consistently higher country-level averages (9$15 \%)$. Concerning people involved in paid work, the survey results are dissimilar across cases. The OP and TWFY respondents are more involved in paid work than their average country population,

\footnotetext{
${ }^{6}$ Escher's survey comprised a category called 'other education' (5\% of respondents). Moreover, the category 'doctoral degree' was absent.

7 In the ESS1-2002, the category 'doctoral degree' was not present.

${ }^{8}$ According to an elaboration of the data on the website the Long Term Economy (2009), the rate of researchers as share of the population is $0.002 \%$ in Italy, $0.003 \%$ in France and $0.004 \%$ in the UK.
} 
while the opposite is true for the ND respondents (see Figure 2). Another significant difference between the respondents and their fellow-citizens concerns the category of people in education. All the projects have larger shares of people in education than does their respective country, OP and TWFY even having close to double the share. Strangely, OP stands out from the rest of the projects as having three times fewer retired people with respect to the Italian average. This could indicate that elderly people in Italy do not have sufficient motivation and skills to engage online.

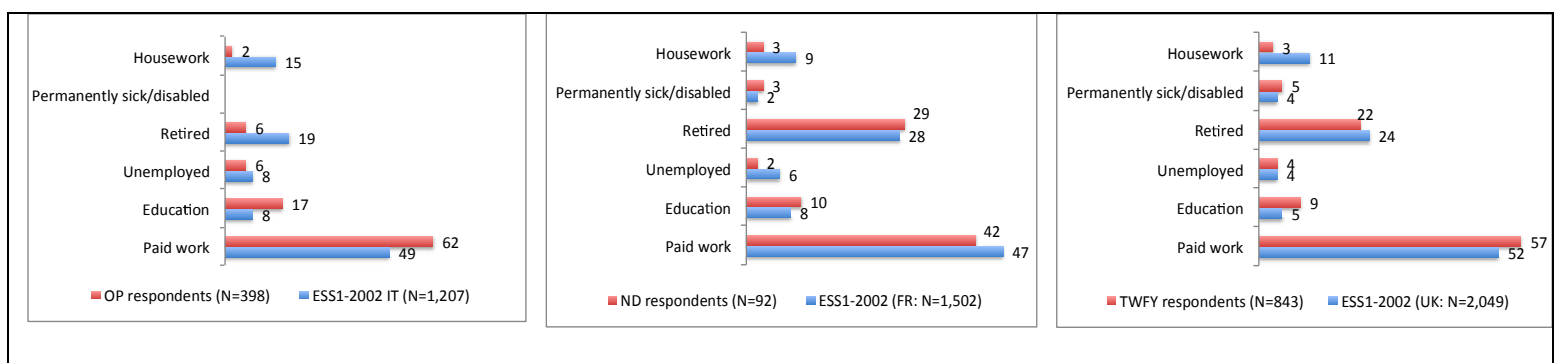

Figure 2. Main activity during the last seven days (\%) (Author's surveys 2011; Escher 2011; ESS12002) $)^{9}$

The two cohorts where the gap between survey respondents and their respective country population is greatest - persons involved in paid work and housework - have been tested against the data for people who have engaged in alternative forms of politics (see Table 3). The results indicate that the survey respondents are more similar to the people who have engaged in alternative forms of politics, as opposed to the general country population. The only exception is the category of paid workers in France, where the ND respondents amount to $42 \%$ and are more similar to the country population (47\%) as opposed to their politically active fellow-citizens $(56 \%$ average).

Table 3. The share of persons (i) doing housework, looking after children or others; or (ii) involved in paid work, who have engaged in politics in alternative ways in Italy, France and the UK (\%) (Authors' surveys 2011; Escher 2011; ESS1-2002)

\begin{tabular}{lrrr|rrr}
\hline & Housework etc. & \multicolumn{4}{|c}{ Paid work } \\
\hline & IT & FR & UK & IT & FR & UK \\
\hline Averages across the country-level statistics & 36 & 9 & 11 & 32 & 47 & 52 \\
Averages among project respondents (OP, ND, TWFY) & 2 & 3 & 3 & 62 & 42 & 57 \\
Contacted politician/government official & 6 & 8 & 8 & 65 & 52 & 51 \\
Taken part in a lawful demonstration & 5 & 3 & 4 & 55 & 60 & 59 \\
Signed a petition in & 9 & 7 & 11 & 63 & 55 & 58 \\
Averages across the three participation indicators & 7 & $\mathbf{6}$ & $\mathbf{8}$ & $\mathbf{6 1}$ & $\mathbf{5 6}$ & $\mathbf{5 6}$ \\
\hline
\end{tabular}

\footnotetext{
${ }^{9}$ The categories "Other activity" and "Community/military service" were omitted from the graph because of the space limit. These are the results for: (i) "Other activity": Italy ESS1=2002: 1\% and OP 6\%; France ESS1=2002: $1 \%$ and ND 10\%; the UK ESS1=2002: 1\% and OP 0\%; and (ii) "Community/military service": Italy ESS1=2002: 0\% and OP 1\%; France ESS1 $=2002: 0 \%$ and ND 0\%; the UK ESS1 $=2002: 0 \%$ and OP 0\%
} 
Turning to disability, the project respondents generally have fewer disabilities than their conationals (see Figure 3). The averages for TWFY and the UK respondents - serious disability and not - sum up to being almost the same (25\% and $26 \%$ respectively). At the same time, TWFY users have a slightly higher share of people that are marginally ill or disabled with respect to the UK population ( $3 \%$ higher average). It is also noteworthy that the survey results concerning severe disability are generally confirmed by answers to the question about respondents' main activity during the last seven days, where a response option was 'permanently sick/disabled' (results: $0 \%$ in OP, $3 \%$ in ND and $5 \%$ in TWFY, see Figure 2). Again, the country-level results tend to correlate: the UK population and TWFY respondents have the highest share of disabled respondents; the French population and the ND respondents occupy a middling position; and the Italians and the OP respondents have the lowest share of disabled people.

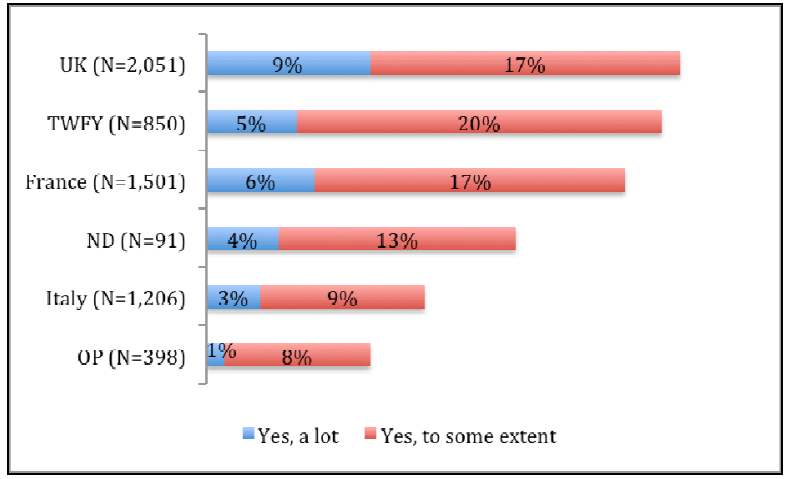

Figure 3. Respondents with health problems and disabilities compared to country averages (Author's surveys 2011; Escher 2011; ESS1-2002) $^{10}$

The survey data was compared with the equivalent cohorts in ESS1-2002 who have (in addition) engaged in alternative forms of political participation (see Table 4). The analysis shows that the share of disabled among people involved in alternative participation is slightly higher than among the OP and ND respondents. However, if we compare the respondents with those who have taken part in a demonstration, the situation is reversed: the share of disabled among project users is notably higher (in the case of TWFY, five-times higher). This could indicate that the parliamentary informatics projects at hand have at least enabled some physically disabled people to engage in politics.

\footnotetext{
${ }^{10}$ The TWFY data originates from Escher's survey (2011). His survey did not contain the nuance of 'a lot' or 'some extent' of disability but had two separate questions: (1) "Do you have a health problem or disability, which prevents you from doing every day tasks at home, work or school or which limits the kind or amount of work you can do?" ('yes' or 'no'). $20 \%$ answered 'yes'. (2) "Which of these descriptions best describes your current situation?" One of the answer options was "permanently sick or disabled " and $5 \%$ answered 'yes'.
} 
Table 4. Respondents with health problems and disabilities engaged in alternative forms of participation (Authors' surveys 2011; Escher 2011; ESS1-2002 ${ }^{11}$ )

\begin{tabular}{lrrr}
\hline & IT & FR & UK \\
\hline Averages across the country-level statistics & 12 & 23 & 26 \\
Averages among project respondents (OP, ND, TWFY) & 9 & 17 & 25 \\
Contacted politician/government official & 11 & 19 & 21 \\
Taken part in a lawful demonstration & 5 & 14 & 5 \\
Signed a petition in & 14 & 32 & 37 \\
Averages across the three participation indicators & $\mathbf{1 0}$ & $\mathbf{2 2}$ & $\mathbf{2 1}$
\end{tabular}

Many of the project respondents are also politically active offline. An overwhelming majority voted in the last parliamentary elections: $89 \%$ of OP respondents and $98 \%$ of ND respondents. ${ }^{12}$ These turnout levels are higher compared to the national averages, especially in the case of France (see Table 5). A large share (between 51-83\%) of respondents is also engaged in unconventional political activities. These figures appear especially striking when compared to the much lower - in some cases five or six times lower - national participation rates.

Remarkably, although France tends to have higher unconventional participation rates than Italy, ND users score lower in comparison to OP users on the same indicators. The only exception is the indicator concerning contacting media or civil servant/politician, where ND users score higher than OP respondents. This could imply that the respondents are already a selection of highly politically active people; hence, the country context probably has a minor influence on their activity rates.

\footnotetext{
${ }^{11}$ The relevant ESS1-2002 question was "Are you hampered in your daily activities in any way by any longstanding illness, or disability, infirmity or mental health problem?" And the answer options were: (i) Yes, a lot; (ii) Yes, to some extent; (iii) No; (iv) Don't know. The table represents aggregated data for the response options 'Yes, a lot' and 'Yes, to some extent' under question.

${ }^{12}$ The voting data is not available for TWFY users.
} 
Table 5. Share of respondents and country populations involved in political activities (Authors' surveys 2011; IDEA $2008^{13}$; ESS1-2002; INSEE 2010 ${ }^{14}$ )

\begin{tabular}{llrrrrrr}
\hline & \multicolumn{2}{c}{ OP } & Italy & \multicolumn{2}{c}{ ND } & France \\
& $(\mathrm{N})$ & $(\%)$ & $(\%)$ & $(\mathrm{N})$ & $(\%)$ & $(\%)$ \\
\hline Voted in the last parliamentary/national elections & 341 & $89 \%$ & $85 \%$ & 91 & $98 \%$ & $60 \%$ \\
Contacted civil servant/politician & 210 & $53 \%$ & $12 \%$ & 52 & $57 \%$ & $17 \%$ \\
Participated in a demonstration/protest & 273 & $69 \%$ & $11 \%$ & 51 & $55 \%$ & $17 \%$ \\
Signed petition & 333 & $83 \%$ & $18 \%$ & 73 & $78 \%$ & $34 \%$ \\
Posted on an online political forum & 234 & $59 \%$ & - & 46 & $51 \%$ & $34 \%$ \\
\hline
\end{tabular}

In addition, TWFY respondents are more politically engaged than their average reference population: $28 \%$ have participated in demonstrations, signed a petition, contacted a politician, boycotted a product, donated money or displayed a campaign badge, in comparison to $18 \%$ of the British population (ESS1-2002). Unsurprisingly, TWFY users' participation takes place more often online $(18 \%)$ than offline (10\%) (Escher 2011).

It is also noteworthy that a large share of OP and ND respondents have never engaged in any of the political activities under consideration: their share oscillates between $30-45 \%$ for all activities, except for petitioning in which about one fifth of the respondents have never engaged (see Table 6). Similarly, close to half of TWFY users have not engaged in any other political activity apart from using the TWFY website. $60 \%$ of TWFY users have never even looked up information about their MPs before they visited the site. What is more, one in five users (i) has not been politically active within the last year, (ii) have not been part of any political or community groups, and (iii) has tried to find information about representatives for the first time with the help of TWFY (Escher 2011, p. 5). This indicates that the projects have enabled a certain number of people to engage in politics.

\footnotetext{
${ }^{13}$ Country-level statistics for parliamentary elections originate from IDEA's website. Statistics for Italy date back to the 2008 elections, and those of France to the 2007 elections.

${ }^{14}$ All the French statistics originates from the ESS1-2002. The only exception is the answer option "Posted on an online political forum/discussion group": the statistical data referring to the country-level originates from INSEE (2010).
} 
Table 6. Respondents who never engaged in any of the political activities under consideration (Author's surveys 2011)

\begin{tabular}{lrrrr}
\hline & \multicolumn{2}{c}{ ND } & \multicolumn{2}{c}{ OP } \\
& $\%$ & $(\mathrm{~N})$ & $\%$ & $(\mathrm{~N})$ \\
\hline Posted on an online political forum & $43 \%$ & 39 & $40 \%$ & 158 \\
Contacted politician/media & $41 \%$ & 38 & $44 \%$ & 176 \\
Demonstrated & $41 \%$ & 38 & $30 \%$ & 119 \\
Signed petition & $22 \%$ & 20 & $17 \%$ & 67 \\
\hline
\end{tabular}

In sum, the representation of many groups of citizens turns out to be skewed in the three projects. Women are clearly underrepresented among the project respondents. The level of education of respondents is well above the national average. Moreover, a very low share of respondents does the housework, and looks after children or others. Generally, disability is less common among the project respondents with respect to both their country population and to people involved in alternative participation. However, it seems that the parliamentary informatics projects at hand could have enabled some physically disabled people to engage in politics.

The user survey and country-level results seem to be correlated: the differences between cohorts are visible and tend to follow the country pattern (i.e. if the UK population and TWFY respondents exhibit the highest indicators; the French population and the ND respondents normally occupy a middling position; and the Italians and the OP respondents show the lowest indicators). The socio-economic context seems to influence certain project-level indicators such as education, occupation and disability - country-distinct patterns emerge when different countries are compared.

What is more, parliamentary informatics users are more similar to their co-nationals who are involved in activities like petitioning, demonstrating and contacting politicians; than to their respective country population. Further corroborating the finding above, the survey analyses show that the majority of project respondents are already politically active. The high level of unconventional political participation among project respondents is in line with previous findings by Bimber (2003) and Jensen (2006). Finally, on a positive note, the analysis shows that e-democracy projects also manage to capture the attention of a considerable share of respondents who are normally politically inactive.

\subsection{Accountability}

The accountability criteria implies that users should be able to access balanced and comprehensive information about the parliamentary issues at stake. It is assumed that accountability is affected by site moderation and sources of information used.

It turns out that the accountability criterion is the strong point of parliamentary informatics projects. The projects collect valuable information and present it in a more accessible way than other, more centralised venues such as physical parliamentary offices that keep paper records, or even with respect to parliaments' official websites. They merge data in ways that allow citizens or civil society organisations to extract specific information of their interest, e.g. the voting pattern of a party on a particular topic. This user-friendly approach to providing information is more compatible with the Internet habits of today's users (Fung et al. 2010). What is more, the interactive features of parliamentary informatics allow citizens to debate politics. This should facilitate development of their preferences and perspectives, and allow them to better question their representatives. 
The site users are fairly well convinced that the information on these platforms is accurate. As shown in Figure 4, a significant majority of TFWY $(98 \%)$, OP $(83 \%)$ and ND $(66 \%)$ respondents say that the site information is objective and few users disagree with this statement (1\%-7\%). It is noteworthy that the ND users are more hesitant: almost every fourth respondent doubts that the information is objective. ${ }^{15}$

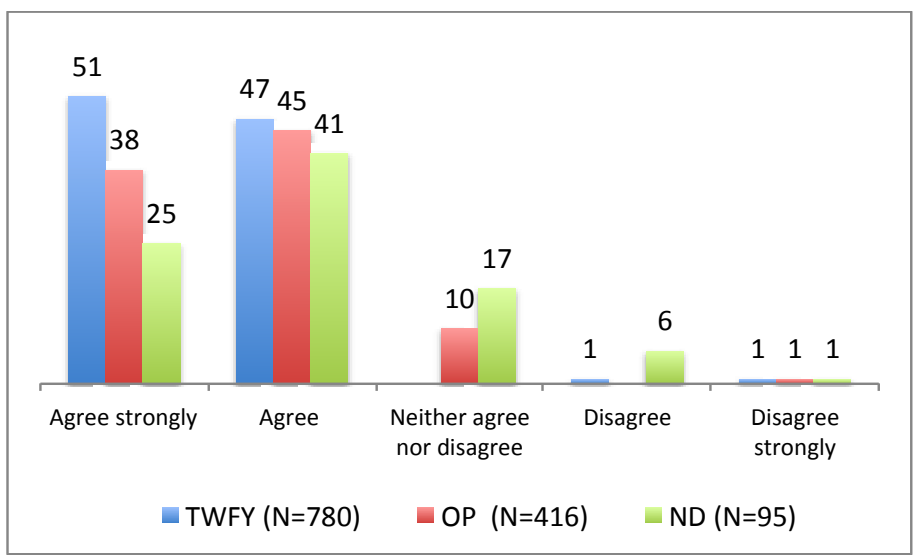

Figure 4. How much do you agree or disagree with the following statement? "(The TWFY/OP/ND website) provides information in an impartial and objective way" ${ }^{\text {"16 }}$ (Author's surveys 2011, Escher 2011)

Moreover, some users believe that parliamentary informatics projects present information in a more neutral and factual way in comparison to the partial picture offered by traditional media channels. Frame 1 illustrates some relevant comments from users.

"It is good to see what was actually said rather than hearsay from the media" (Escher 2011, p. 30) "You can access factual information rather than rely on the media's interpretation" (Ibid)

"The site, I like it a lot, (..) it serves the purpose of understanding facts without the influence of external impulses (Author's survey of OP 2011)

Frame 1. Users confronting parliamentary informatics projects information with other sources

Accountability is assumed to be affected by site moderation. Scholarly literature emphasizes that moderators should be specifically trained, well-informed about the subject at stake and independent of the authority sponsoring the initiative (Fagotto and Fung 2009; Smith 2009). Examining the projects at hand, it emerges that moderators are generally persons from the project team. An exception is the case of OP, where some of the moderators are recruited among site users. They are not remunerated and work quite independently from the association in charge of OP.

\footnotetext{
${ }^{15}$ The calculation behind the statement "almost every fourth respondent doubts that the information is objective" is based on the percentages of respondents who answered 'neither agree nor disagree' (17\%), 'disagree' (6\%), and 'disagree strongly' (1\%).

${ }^{16}$ The question in the TWFY survey (Escher 2011) was formulated in the following way: "How much do you agree with the following statement? "TWFY provides information in and unbiased and unpartisan way". The response options: strongly disagree, disagree, agree, strongly agree, don't want to answer. There was no option of 'neither agree nor disagree'.
} 
The author's interviews reveal that OP and ND moderators, who check user-created information, use an ad hoc (as opposed to systematic) approach to verification. They are not necessarily knowledgeable about the issues posted or debated by users, which probably makes it more difficult for them to spot erroneous information or manipulation by users. Moreover, the moderators have a rather liberal approach to verification, i.e. they assume that users are aware of the possibility of getting incorrect or false information and are capable of spotting it. The ad-hoc approach to moderation applied by the OP and ND seems to work out well. So far, no user has ever reported false information and the projects have never banned anyone from their platforms. The OP and ND moderators mainly report misplaced posts or irrelevant information. TWFY does not store data about cancelled posts or banned users but, considering that they have kept a liberal approach to moderation, the manipulation of information has probably never been an issue.

On OP, there has been only one known occasion of manipulation of information. In connection with the draft law S.1142 on the creation of a register for health professionals and nurses, a user tried to influence the discussion without revealing his/her real identity and agenda. The draft was heavily debated and received a lot of comments and votes among OP users. The abuser used an automatic application, which allowed him to register and vote under several names. This was quickly spotted by OP staff, which blocked the relevant user account. Apart from this attempt to trick the system, the OP team also suspects that some MPs or their press office staff have made posts under other names than their own. However, this is not confirmed by any hard evidence.

The projects under study do not apply any moderator guidelines. In the case of OP, moderators follow the detailed site rules. ${ }^{17}$ These rules (very similar to the TWFY House Rules ${ }^{18}$ ) include the ban against using an identity that is not your own, disclosing personal information that relates to other users of the site against their will, offending the dignity and reputation of individuals, or insulting people, races, genders, religions, economic or political opinions. Moreover, the information entered by users should be carefully documented and verified before it is published, or else it risks being removed. ND does not apply any rules at all; the only condition is that users respect the French law. All three projects operate a 'reactive moderation', meaning that user contributions are published on the web site immediately. Where they violate the law or go against the rules, the contributions are blocked or deleted. TWFY only checks whether an annotation breaches their House Rules if a user expresses his/her concern via the Report link, which can be found next to every annotation. If the Rules are broken once, the user is let off with a warning. Both TWFY and OP ask the author if (s)he want to rephrase and resubmit his/her original annotation before it is deleted.

Accountability is also assumed to be affected by the sources of information used by edemocracy projects. In particular, the premise is that if official sources are used (as opposed to e.g. user-created information), accountability is more likely to be enhanced. This assumption is based on the widely acknowledged notion that transparency generates accountability, i.e. public access to official information allows the impact of government policies to be assessed, so improving accountability. Different kinds of transparency might (or might not) lead to different kinds of accountability. According to Fox (2007, p. 667), transparency can be either 'clear' or 'opaque', while accountability can be either 'soft' or 'hard'. Clear transparency should reveal reliable information about institutional performance, while opaque transparency stands for unreliable information or for the dissemination of information that does not reveal how institutions behave in practice.

In practice, certain data in the public domain is not easily accessible to lay citizens and has to be translated into comprehensible information by either journalists or watchdog organisations (Fox

\footnotetext{
${ }^{17}$ The site rules are available at: http://parlamento.openpolis.it/static/regolamento

${ }^{18}$ The site rules are available at: www.theyworkforyou.com/houserules
} 
2007). This type of translation is one of the key activities of the parliamentary informatics projects under study. They transform opaque into clear transparency by offering easy access to information about parliaments and by shedding light on the behaviour of members of parliament. This allows interested parties like opinion makers, journalists and ordinary citizens to be adequately informed.

Nevertheless, clear transparency on its own does not guarantee accountability. In keeping with Fox (2007), 'soft' accountability contains the possibility to call those in authority to justify their decisions (also termed 'answerability') while hard accountability goes further by involving the possibility of sanctions (Fox 2007, p. 668). As shown by Figure 5, transparency and accountability overlap: clear transparency is a form of soft accountability.

\begin{tabular}{|c|c|c|}
\hline Transparency & Accountability \\
\hline Opaque & Clear & \\
Dissemination and access to information & Soft \\
\hline Institutional 'answerability' & Sanctions \\
\hline
\end{tabular}

Figure 5. The relationship between transparency and accountability (Fox 2007, p. 669)

Soft accountability is put in practice by projects like OP, ND and TWFY, which improve the value of existing data by producing user-friendly information about institutional behaviour. However, the projects under study are not able to guarantee any action with regard to the information revealed (i.e. hard accountability).

In terms of democratic intentions, parliamentary informatics projects generally aim at improved transparency and accountability. Most of them were developed in response to the challenge of limited and dispersed information about parliamentary activities. And today OP, ND and TWFY are allegedly the key unified and easily accessible points of parliamentary information in their respective country. TFWY was the first initiative of its kind worldwide. Likewise, nothing similar existed in Italy or France before the launch of OP and ND. Their platforms manage to organise information in a more accessible way than the national parliaments that publish online information about their activities. In Escher's survey, British users often highlighted that TWFY is more usable than government websites (Escher 2011, p. 29).

On the whole, parliamentary informatics projects have made official information more accessible to all citizens capable of using computers, as opposed to only experts and specialized journalists (Petiot 2010). With the help of these platforms, people can take an informed and well-grounded stance on political issues. In response to the need for even more manageable information, OP and TWFY enable the integration of official data with the more intelligible descriptions and clarifications of legal acts provided by users. What is more, parliamentary informatics projects transform information into a political resource that enables citizens and civil society organisations to identify the weak links in the chain of public action and to bring forward cases of mismanagement or corruption.

However, the democratic quality of parliamentary informatics projects is not free from flaws. The case of TWFY reminds us that accessibility of information - besides being an aspect of accountability - is also closely related to the concept of equality. According to Escher's survey (2011), the majority of users $(80 \%)$ found the information they were looking for and considered the site to be easily navigable and well structured. Nevertheless, there were significant differences between users who found relevant information and those who did not. Curiously, the differences were not significant when it came to political knowledge but were mainly demographic. Those who failed to find what they were looking for were more often:

- women (they failed twice as often as men); 
- older people (especially aged 55-64);

- less likely to have a university degree ( $54 \%$ vs. $66 \%)$;

- twice as likely to have a disability than successful users.

It is worth noting that this was not a question of becoming familiar with the site: half of the unsuccessful users were in fact repeat users who still failed to find information (Escher 2011).

Summing up the findings, the objectivity and transparency of information are probably the greatest contributions to democracy by parliamentary informatics projects. By facilitating access to official information, they enable citizens to demand explanations from their representatives, thereby backing soft accountability (Fox 2007). In line with the claims of Fung et al. (2010), the major value of parliamentary informatics projects is that they present official information in a more user-friendly and constructive way with respect to governmental stakeholders. This is also most likely the reason for their success among users: the majority is convinced about the objectivity of the information provided. TWFY, OP and ND are designed in such a way as to allow many participants to explore, learn about issues and consider the merits and trade-offs between several options. All three projects have very limited moderation, with few personnel and resources dedicated to this task. Overall, they are more promoters than censors of deliberation. Despite this liberal and unstructured approach, there is basically no falsification or abuse by users.

\subsection{Responsiveness}

Responsiveness implies that policy-makers are responsive to citizens' needs and demands, and do their outmost to incorporate their opinion into policy making. The literature points to a number of key factors that can affect the outcomes of e-democracy projects: citizens' mobilisation for a cause, the visibility of the cause or the project in the media; and policy-makers' support for the project or project outputs. (Creasy et al. 2007; Fagotto and Fung 2009; Janssen and Kies 2004; Smith 2009; Macintosh and Whyte 2006; Papadopoulos and Warin 2007). The relation between some of these independent variables (not all, due to limited space) and the dependant variable 'responsiveness' will be explored in this section of the paper. In short, the democratic intentions of the parliamentarians, including their political support, should affect their responsiveness to the suggestions made by the project users or driven by civil society on parliamentary informatics platforms.

In practice, a global survey among parliamentary monitoring organisations shows that parliamentary watch activities can help identify deficiencies within a parliament's overall framework and may uncover the reasons why individual MPs underperform. This even seems to have some beneficial effects on the behaviour of individual MPs. However, it is apparently more difficult to influence collective behaviour or bring about institutional reform (Mandelbaum 2011).

Among the cases at hand, the available evidence suggests that TWFY has had the most success in impacting on politics among the three projects. According to some commentators, mySociety (the organisation in charge of TWFY) managed to reverse the UK Government decision to exempt MPs from the Freedom of Information Act (a decision that would have relieved them from publishing their expenses). Moreover, the fact that $2 \%$ of visits to the TWFY site can be directly attributed to the UK Parliament, while the additional 2-3\% come from other government sources (Escher 2011) give us good reason to believe that state actors are interested in, and responsive to, TWFY.

Regards Citoyens (the organisation in charge of ND) claims to have influenced the decision of the National Assembly to apply fine rules for the absence of MPs from obligatory sessions, as well as to have prompted MPs to increase their presence during parliamentary sessions. The association also argues that ND was widely used during the latest electoral campaign by various parliamentary candidates. At the same time, the French minister for relations with Parliament, Alain Vidal, has voiced disapproval regarding ND. According to the minister, the ND statistics have had a 
direct and harmful impact on the parliamentary debate (PC INpact 2012). In particular, he claims that ND slows down the parliamentary work as MPs increase the number of interventions to improve their statistical scores on the website (Le Lab Europe 1 2012). His criticism is directed at the way the site counts the number of times an elected official speaks on the floor of Parliament. Given that the minister does not offer any evidence to support his claim, Regards Citoyens has conducted an analysis of parliamentary debates between 2007-2012. This analysis shows the opposite effect: recent debates have been briefer than those in the years prior to the launch of ND (Regards Citoyens 2012). In any case, the minister's intervention shows that the ND is well-known among the parliament officials and that it might have influenced at least some of their selfperceptions.

The French minister is not alone in his concerns. Different MPs and parliamentary monitoring organisations around the world affirm that the rating of MP participation can induce an upswing in quantity, as opposed to quality, of debate (Mandelbaum 2011). TWFY received similar accusations back in 2006 when the Times published an article that claimed that MPs were submitting more and more questions in order to improve their rankings on TWFY (Eaves 2012). The Times maintained that MPs were "making forgettable contributions to debate" and tabling numerous written questions simply to boost their statistics on TheyWorkForYou (Hurst 2006). This triggered a debate in the House of Commons on the increase in questions, led by Peter Luff (Luff 2006). In response, MySociety removed the absolute rankings, added some more explanatory text, and held a meeting with the Parliament to discuss better metrics. Even after this, certain MP have complained about representatives who tailor their work programmes to gain high scores on the TWFY website (Salter $2010^{19}$ ).

An indication of the influence of parliamentary informatics projects is also illustrated by the findings from the ND survey, which shows that five respondents were contacted by MPs or civil servants regarding their proposals. Three of them received a response formulated in general or vague terms. One person learnt that a similar proposal had already been processed by the parliament, and another one was told that his/her proposal would be incorporated into a political decision. This should point to a certain interest by the Parliament, and - above all - to the potential to influence it. However, one must be careful of judging this result since the number of survey respondents was quite limited. It is also plausible that those who were more active in making proposals on ND and those who received feedback were also more eager in replying to the survey. ${ }^{20}$

At the same time, a large majority of OP and ND respondents (circa 70\%) had strong expectations about finding supporters for their causes (see Figure 6). ${ }^{21}$ Just as many ND respondents expected that their input would be considered by MPs, and $37 \%$ of them were even strongly convinced about it. What is more, about half of ND and one third of OP respondents believed that their participation would lead to political action. This is rather surprising, as OP and ND do not promise any direct communication channel with Parliaments. Moreover, about half of OP and ND respondents were expecting to attract attention for their cause from the general public or media.

\footnotetext{
${ }^{19}$ Citation of Salter (2010): "There are those ridiculous bespoke websites, including TheyWorkForYou.com. Tragically, I know hon. Members of the 2005 intake who have tailored their work programmes to get a high score on the TheyWorkForYou website. As we know, an intervention used to count the same as a speech and parliamentary questions were asked to drive up a score, rather than for a purpose."

${ }^{20}$ The question about whether users were contacted by MPs/civil servants regarding their proposals was not included in the author's survey of OP because of limited space.

${ }^{21}$ There is no data about expectations of TWFY respondents.
} 


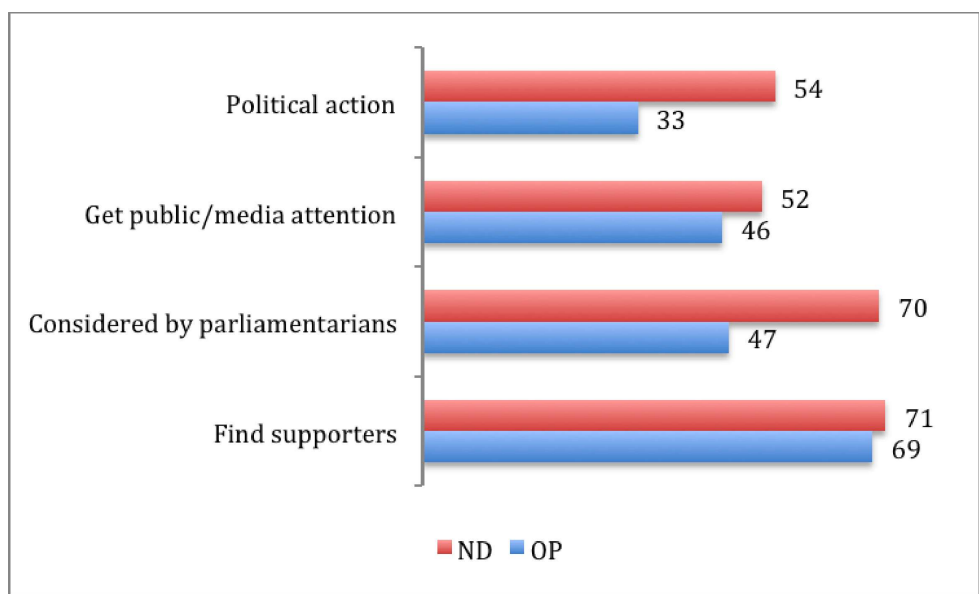

Figure 6. Expectations of ND and OP respondents (\%) (Author's surveys 2011)

User expectations about feedback from their representatives is confirmed by the fact that an overwhelming majority of OP users (circa $80 \%$ ) would be eager to communicate with and advance proposals to MPs (see Figure 7). These respondents are more numerous, and more strongly convinced, in comparison to those who would like tools to communicate with each other (74\%). In short, project users have very strong expectations about the parliamentary response to their inputs and are eager to interact with MPs.

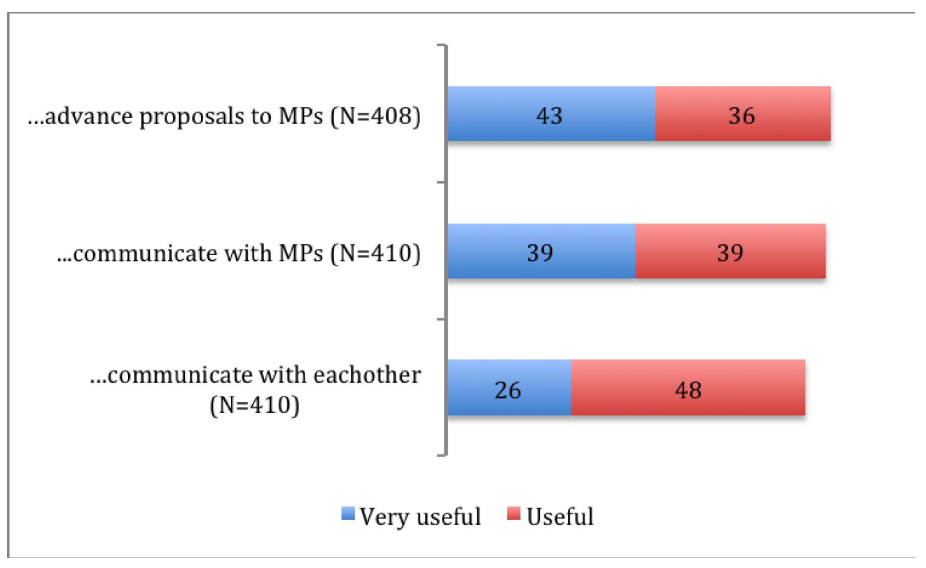

Figure 7. Respondents view about how useful it would be to add new communication tools to OP (\%) (Author's survey 2011) ${ }^{22}$

My assumption is that the political responsiveness to parliamentary informatics project could be affected by the democratic intentions and the extent of political support of actors who are associated with this type of project, i.e. those who are running the projects and state actors to whom the projects are (indirectly) addressed. The interviews with the project teams, the review of project documents and online material show that the primary goal of OP, ND and TWFY is to provide user-friendly and free access to public data about parliamentary activities. All three

\footnotetext{
${ }^{22}$ Answers to the question: "Do you think it would be useful to add new tools to OP? Tools that allow users to..." These questions were asked only to OP users because the OP team was considering adding new instruments to their site and asked to include an additional question where respondents evaluated how useful a number of tools would be.
} 
associations running the projects promote the release of public data free of license. ${ }^{23}$ The organisations behind the projects in the study all emphasize the value of transparency, impartiality and accountability, and consider that communication between citizens and politicians can raise the quality of decision-making and improve democracy. The overarching aim of the three projects is to involve citizens in policy-making. By offering tools for citizens' engagements in parliamentary activities (e.g. comments or voting of laws), the projects adapt a bottom-up perspective: citizens are seen as initiators and/or producers rather than just consumers of policy (Macintosh 2003).

At the 'receiver end', the Italian and French parliaments tend to take a conservative approach to e-democracy. According to the project coordinators of the Italian and French cases respectively, some of the MPs consider the projects not so much as a chance to interact with citizens but more as an opportunity to improve their personal or party visibility, while some French MPs seem to show enthusiasm about e-democracy projects mainly in order to improve their image as supporters of accountability. One of the members of the OP team describes the attitude of public authorities towards e-participation in the following way (Steinberg 2007):

“(...) administrators are interested in e-participation projects, but they want to reduce the possibility of issues emerging directly from citizens, and of course they try to change the nature of the project from a participative one, into a consultative one. A kind of Poll 2.0, if one wants to be cynical."

The gap between the intentions of the project teams and those of the parliamentary actors is exemplified by the case of ND. The ND team struggles to extract some of the necessary data from the Assembly's web site and has not been able to establish any collaboration regarding data with the apposite Assembly office, despite several attempts (Petiot 2010). According to Mandelbaum's global survey (2011) among nearly 200 parliamentary monitoring organisations, the key challenges facing these organisations are difficulties in gaining access to parliamentary information (cited by $63 \%$ ). Parliaments often question the methodologies used to evaluate parliamentary activity or the organisations' (presumed) political allegiances. The lack of support for parliamentary monitoring organisations is illustrated by the fact that $35 \%$ of them encounter resistance to their activities by MPs, parties or parliamentary staff (Mandelbaum 2011).

However, there are also some hints of political support or at least interest for parliamentary informatics projects. This support is illustrated by a relatively high response to a survey among MPs carried out by OP. The survey was launched in February 2010 and asked MPs about the best way to make a qualitative assessment of parliamentary activities. The response rate reached $16 \%$ (156 out of 952 MPs completed the survey). The MPs advanced some useful proposals for improving OP's performance index, as well as parliamentary practices (e.g. most respondents agreed that the tax files of MPs should be published openly).

The case of TWFY shows even more signs of political support. The current Prime Minister of the UK (at the time the Conservative leader), David Cameron (2009), has praised TWFY and called for a local version of this type of initiative when pledging about more information to people. Some MPs are even citing TWFY when assessing colleagues' performance in parliament (Hands 2009; Attlee 2008; Wishart 2007; Royall of Blaisdon 2008; Eadie 2009). Most MPs seem to be positive towards the project and some even suggest that the Parliament should collaborate with TWFY to improve people's access to information (Prentice 2008). At the same time, others are painfully aware that TWFY reinforces the Parliament's accountability and feel exposed (see Frame 2 below).

"In this technological era, we need to be able to respond quickly and effectively to organised lobby groups. As the technology has moved on, so our response is tracked electronically and very

\footnotetext{
${ }^{23}$ As a case in point, the ND project was initially born out of protest actions against the controversial HADOPI law, which wanted to make some of the file sharing on the Internet illegal. (See a description of the HADOPI law on Wikipedia at: http://en.wikipedia.org/wiki/HADOPI law)
} 
carefully. We know of the website TheyWorkForYou, which tracks responses and how quickly we get back to constituents. More and more, we are living in a goldfish bowl as a result of technology, and the advanced communication techniques used by non-governmental organisations, interest groups, community associations and, yes, political parties. It is wrong that Members of Parliament are expected to do their job, to take the kicks and the brickbats, without the ability to respond in at least a semi-21st century manner." (Salter 2007).

"I agree with what my hon. Friend said about TheyWorkForYou.com and the way in which its measurement of the effectiveness of a Member of Parliament in a performance league table puts Members under incredible pressure." (Harper 2006).

"I am assiduous, as are all my colleagues, in ensuring that questions are answered whenever possible, but we have a problem in the House with researchers trying to prove a point, and with the TheyWorkForYou.com website, which seems to measure Members' work in quantitative rather than qualitative terms." (Straw 2006).

"The wonderful website, theyworkforyou.com, which specifies in providing painstakingly and often painful details on all our appearances and interventions in this House (...)." (Royall of Blaisdon 2008).

Frame 2. Living in a goldfish bowl - what MPs say about TFWY

In short, our analysis points to few instances when projects have achieved political influence. TWFY has a sizable political responsiveness, arguably the strongest among the three projects. In line with the initial assumption about influencing variables, TWFY also shows best results in terms of political support from parliamentarians. OP only shows weak signs of MPs' interest and ND does not have any political support at all.

In contrast to the scattered responsiveness, ND and OP users have very strong expectations about response to their inputs. They expect their input to be considered by MPs and believe that their participation will lead to political action. An overwhelming majority of OP users (circa $80 \%$ ) are eager to advance proposals and communicate with MPs. This implies that the current level of political responsiveness is inadequate.

\section{Conclusion}

This paper shows that parliamentary informatics projects achieve mixed results in terms of democratic quality. In theory, parliamentary informatics projects are intrinsically more inclusive than conventional participation since they offer access to groups of people that are normally excluded from voting, e.g. immigrants that still do not have rights to vote in local or national elections, or those who are under-age. Moreover, parliamentary informatics actually manages to attract some people who are normally not engaged in politics. However, the survey results also show that the project users are probably not very representative of their country populations.

In fact, there is a risk that the majority of those who access parliamentary informatics platforms and express their opinions are well-educated, able men, habitually involved in politics in one way or another. Overall, the surveys confirm Hindman's assumption that online political participation is even less inclusive than offline engagement (Hindman 2008). At the same time, the segments involved offline and online converge, which leads me to assume that existing political inequalities are being reinforced in parliamentary informatics projects - an e-democracy effect already observed by other authors (Bimber 2003; Norris 2001). Even if parliamentary informatics projects manage to involve additional people in politics, it might just be more of the 'usual suspects', while the traditionally uninvolved stay behind. In sum, the lack of equality among participants may pose problems of legitimacy to the outcomes of e-democracy projects. 
Turning to accountability, the objectivity and transparency of information are probably the greatest contributions to democracy by parliamentary informatics projects. By facilitating access to official information, they enable citizens to demand explanations from their representatives, thereby backing soft accountability (Fox 2007). The major value of parliamentary informatics projects is that they present official information in a user-friendlier than the parliaments themselves and in more impartial way than the media. This is also most likely the reason for their success among users: the majority is convinced about the objectivity of information provided. Moreover, TWFY, OP and ND are designed in a way that allows many participants to explore, to learn about issues and to consider the merits and trade-offs between several options.

The academic literature also emphasise that in order to maintain the objectivity of information, moderators should be especially trained, well-informed about the subject at stake and independent of the authority sponsoring the initiative (Fagotto and Fung 2009; Smith 2009). The cases at hand disconfirm this assumption. All three projects are noticeably lacking in resources dedicated to moderation and their moderators are generally not knowledgeable about the issues posted. Despite this unstructured approach, there is basically no falsification by users, and the information tends to be incorrupt.

In terms of political responsiveness to parliamentary informatics, my analysis points to few instances of projects achieving any impact. In the case of TWFY, policy-makers show a certain amount of responsiveness, arguably the strongest among the three projects. But generally parliaments tend to take a conservative approach to e-democracy, considering the projects not so much a chance of interacting with citizens but more an opportunity to improve their personal and party visibility.

In contrast to the parliaments' disregard, citizens have very strong expectation about response. They are eager to interact with MPs, expect their input to be taken into account and believe that their participation will lead to political action. This implies that the current level of political responsiveness is inadequate.

\section{References}

Anduiza E., Jensen M and Jorba L. (2012). Digital Media and Political Engagement Worldwide: A Comparative Study. Cambridge University Press.

Åström J. and Grönlund Å. (2011) "Online Consultations in Local Government - What works, When and Why?" In Coleman, $S$ \& Shane, $P$ eds. Connecting Democracy. (2011). MIT press.

Attlee, Earl (2008). Statement in parliament on 18 December 2008. Accessible on TWFY's website at: http://www.theyworkforyou.com/lords/?id=2008-12-18a.965.0\&s=theyworkforyou\#g993.0

Barber, B. (1984). Strong Democracy: Participatory Politics for a New Age. Berkeley: University of California Press.

Bimber B. (2003). Information and American Democracy: Technology in the Evolution of Political Power. Cambridge University Press.

Blanco I. and Lowndes V. (2011). Does community participation improve the quality of policy making? Exploring and explaining the effects of democratic innovations in neighbouring regeneration. Paper presented at the Joint Sessions of Workshops of the ECPR, St. Gallen, 13-17 April 2011.

Breindl Y. (2010). Critique of the Democratic Potentials of the Internet: A Review of Current Theory and Practice. 43-59. In tripleC - Cognition, Communication, Co-operation 8 (1). http://www.triplec.at/index.php/tripleC/article/download/159/165

Cameron, D. (2009). David Cameron's speech at London's Imperial College (25 June 2009). Published on BBC news homepage at: http://news.bbc.co.uk/2/hi/uk_news/politics/8119047.stm

Creasy S., Gavelin K., Fisher H., Holmes L., Desai M. (2007). Engage for Change: The Role of Public Engagement In Climate Change Policy - The results of research undertaken for the Sustainable Development Commission. Involve. 
Eadie H. (2009). Statement in parliament on 11 February 2009. Accessible on TWFY's website at: http://www.theyworkforyou.com/sp/?id=2009-02-11.14893.0\&s=theyworkforyou\#g14920.0

EIPP (European Institute for Public Participation) (2009). Public participation in Europe. EIPP report from June 2009. Retrieved on 1 July at: www.participationinstitute.org/2009/06/eipp-report-on-public-participation

Escher T. (2011). Analysis of users and usage for UK Citizens Online Democracy. May 2011. London: mySociety / UK Citizens Online Democracy.

European Social Survey (ESS) ESS1-2002. (2002). The ESS1-2002 Edition 6.2. The data is accessible at the ESS website at: http://ess.nsd.uib.no/ess/round1/

Fagotto E. and Fung A. (2009). Sustaining Public Engagement: Embedded Deliberation in Local Communities. Everyday Democracy and the Kettering Foundation Occasional Paper, October 20, 2009.

Fox J. (2007). The uncertain relationship between transparency and accountability. Development in Practice, Volume 17, Numbers 4-5, August 2007.

Fung A, Russon Gilman H. and Shkabatur J. (2010). Impact case studies from middle income and developing countries: new technologies. Transparency and Accountability Initiative. Open Society Foundation.

Hands G. (2009). Statement in parliament on 19 May 2009. Accessible on TWFY's website at: http://www.theyworkforyou.com/pbc/2008-09/Finance_Bill/02-0_2009-05-19a.4.0?s=theyworkforyou\#g4.74

Harper, Mark (2006). Statement in parliament on 28 June 2006. Accessible on TWFY's website at: http://www.theyworkforyou.com/debates/?id=2006-06-28b.344.0\&s=theyworkforyou\#g353.0

Hindman M. (2009). The myth of digital democracy. New Jersey Princeton University Press.

Hurst G. (2012). The MPs who can't stop talking. Dated 27 February 2006. This online articles was published by the Times (not available online any longer) and is cited on http://en.wikipedia.org/wiki/TheyWorkForYou

IDEA 2008. IDEA's webpage: "Voter Turnout”. Accessed in August 2012 at: http://www.idea.int/vt

INSEE (National Institute for Statistics and Economic Studies) (2010). INSEE's website. Data dated 1 January 2010. Retrieved in August 2012 at: www.insee.fr/ )

ISTAT (Italian National Institute of Statistics) (2010). Retrieved in August 2012 at: http://noiitalia.istat.it/index.php?id=7\&user 100ind pi1[id pagina]=35\&cHash=88f349ee2442f49a9da96134ad8582bd

Janssen K. and Kies R. (2004). Online forums and deliberative democracy: hypotheses, variables and methodologies. eWorking papers 2004/01, e-Democracy Centre, Universite de Geneve, Switzerland.

Jensen J. L. (2006). The Minnesota E-democracy project, in Oates S., Owen,D. and Gibson R., ed. (2006). The Internet and Politics: Citizens, Voters, and Activists. New York and London: Routledge.

Le Lab Europe 1 (2012). La froide colère du ministre Vidalies contre les effets pervers du net. Dated 25 August 2012 at: http://lelab.europe1.fr/t/la-froide-colere-du-ministre-vidalies-contre-les-effets-pervers-du-net-4446

Lippa B, Aichholzer G, Allhutter D, Freschi AC, Macintosh A, and Westholm H. (2008). eParticipation: Evaluation and Impact. Demo-net deliverable 13.3.

The Long term economy website (2009). Researchers in R\&D per million people. Retrieved in December 2012 at: http://www.Iteconomy.it/en/2011-09-26-09-04-47/variables/100-researchers-in-rad-per-million-people

Luff, Peter (2006). Peter Luff's intervention, 28 June 2006, in the section "Written Parliamentary Questions" on TWFY website at: http://www.theyworkforyou.com/debates/?id=2006-06-28b.344.0\&s=Peter+Luff+2006-01-01..2007-0101+theyworkforyou+speaker\%3A10373\#g348.0

Lührs R. and Molinari F. (2010). Editorial Note: Sustainable E-Participation. Vol 2, No 2 (2010). eJournal of eDemocracy and Open Government (JeDEM). ISSN: 2075-9517.

Macintosh, A. and Whyte, A. (2006); 'Evaluating how eParticipation changes local democracy'. In Proceedings of the eGovernment Workshop 2006, eGov06, eds Z. Irani and A. Ghoneim. London: Brunel University. 
Mandelbaum A. (2011) for NDI and the World Bank Institute. Strengthening Parliamentary Accountability, Citizen Engagement and Access to Information: A Global Survey of Parliamentary Monitoring Organizations. Accessed on 29 May 2012 at: http://www.ndi.org/node/18101

Norris P. (2001). Digital Divide: Civic Engagement, Information Poverty, And The Internet Worldwide. Cambridge, UK: Cambridge University Press.

OECD (2009). Focus on Citizens. Public engagement for better policy and services. OECD Studies on Public Engagement. Retrieved on August 6, 2011 at: www.sourceoecd.org/governance/9789264048867

Office for National Statistics (2010). Mid-2010 Population Estimates: United Kingdom Retrieved in August 2012 at: http://www.ons.gov.uk/ons/publications/all-releases.html?definition=tcm:77-22371

Papadopoulos Y. and Warin P. (2007). Are innovative, participatory and deliberative procedures in policy making democratic and effective? European Journal of Political Research 46: 445-472, 2007.

PC INpact (2012). NosDéputés: Alain Vidalies souhaite un pôle de réflexion sur la transparence - Interview du ministre en charge des relations avec le Parlement. Dated 28 August 2012: http://www.pcinpact.com/news/73356-nosdeputesalain-vidalies-souhaite-pole-reflexion-sur-transparence.htm

Petiot I. (2010). Le Bien Public. N`197. 5 august 2010. www.bienpublic.com. Link: http://www.regardscitoyens.org/wpcontent/uploads/2010/08/20100805 bienpublic.pdf

Pratchett L. (2006). Understanding E-democracy Developments in Europe. Strasbourg, Council of Europe.

Prentice, Gordon (2008). Statement in parliament on 23 October 2008. Accessible on TWFY's website at: http://www.theyworkforyou.com/whall/?id=2008-10-23b.139.0\&s=theyworkforyou\#g151.0

Regards Citoyens (2012). NosDéputés.fr « dangereux »? Vraiment? Nos réponses au Ministre délégué chargé des relations avec le Parlement. Dated 31 August 2012 at: http://www.regardscitoyens.org/nosdeputes-fr-\%C2\%AB-dangereux$\% \mathrm{C} 2 \% \mathrm{BB}$-vraiment-nos-reponses-au-ministre-des-relations-avec-le-parlement

Royall of Blaisdon, Baroness (2008). Statement in parliament on 3 December 2008. Accessible on TWFY's website at: http://www.theyworkforyou.com/lords/?id=2008-12-03a.4.0\&s=theyworkforyou\#g16.0

Salter, Martin (2007). Statement in parliament on 28 March 2007. Accessible on TWFY's website at: http://www.theyworkforyou.com/debates/?id=2007-03-28b.1513.0\&s=theyworkforyou\#g1531.1

Salter, Martin (2010). Statement in parliament on 7 April 2010. Accessible on TWFY's website at: http://www.theyworkforyou.com/whall/?id=2010-04-07b.295.0\&s=theyworkforyou\#g299.1

Scharpf F.W. (1997). Economic integration, democracy and the welfare state. Journal of European Public Policy, vol. 4, no. 1, 18-36.

Smith G. (2009). Democratic Innovations- Designing institutions for citizen participation. Cambridge University Press.

Steinberg T. (2007). Interview with Italian eDemocracy site builder Guglielmo Celata. Friday, September 14th, 2007. Published on the MySociety web site: http://www.mysociety.org/2007/09/14/interview-with-italian-edemocracy-sitebuilder-guglielmo-celata/

Straw, Jack (2006). Statement in parliament on. 20 July 2006. Accessible on TWFY's website at: http://www.theyworkforyou.com/debates/?id=2006-07-20b.455.0\&s=theyworkforyou\#g461.1

United Nations Statistics Division (2012). Data updated in 2012. Source: http://unstats.un.org/unsd/mdg/SeriesDetail.aspx?srid=557

Wishart, Pete (2007). Statement in parliament on 6 March 2007. Accessible on TWFY's website at: http://www.theyworkforyou.com/debates/?id=2007-03-06b.1390.0\&s=theyworkforyou\#g1460.1

Wojcik S. (2007). Ch. How does eDeliberation work? A study of French local electronic forums. In Avdic A., Hedström K., Rose J., Grönlund Å. (2007) Understanding eParticipation - Contemporary PhD eParticipation Studies in Europe. Örebro University Library. 


\section{About the Author}

\section{Alina Ostling}

I am a PhD candidate at the European University Institute (EUI) in Florence, Italy. My research interests include edemocracy/e-participation, civic engagement and democratic innovations like Voting Advice Applications (VAAs) and parliamentary informatics. I am particularly interested in understanding how new media are used in public participation processes and how they can strengthen citizens' role in politics. Prior to embarking on my PhD, I have worked for an international science policy consultancy and coordinated democratic governance projects at the United Nations Development Programme (UNDP). 